\title{
Site amplification and strong ground motion of the 2007 Noto Hanto, Japan, earthquake estimated from aftershock observation
}

\author{
Masayuki Yoshimi and Kunikazu Yoshida \\ Geological Survey of Japan, National Institute of Advanced Industrial Science and Technology, Tsukuba, Ibaraki 305-8567, Japan
}

(Received July 10, 2007; Revised September 18, 2007; Accepted October 4, 2007; Online published March 3, 2008)

\begin{abstract}
Site amplifications in the lowlands most affected by the 2007 Noto Hanto earthquake, Monzen, Anamizu, and Wajima, are examined using aftershock records observed at eight temporary seismic stations installed just after the mainshock and at two K-NET stations. The predominant frequencies of spectral ratios at alluvium sites in Anamizu and Wajima are approximately $1 \mathrm{~Hz}$. Site amplifications at the alluvium sites are successfully reproduced from 1-D response analysis, except for that at ISK005 where 2-D or higher amplification effects are inferred to play a significant role. A source model composed of two asperities reproduces the ground motions of the mainshock using the empirical Green's function method. The seismic moments of the asperities are $3.76 \times 10^{18} \mathrm{~N} \mathrm{~m}$ and $2.21 \times 10^{18} \mathrm{~N} \mathrm{~m}$, respectively. Peak ground velocity (PGV) at alluvium sites during the mainshock are estimated to be $70-110 \mathrm{~cm} / \mathrm{s}$ for Monzen, $50-110 \mathrm{~cm} / \mathrm{s}$ for Anamizu, and 60-70 cm/s for Wajima. Key words: Spectral ratio, aftershock observation, local site effects, source model, empirical Green's function method.
\end{abstract}

\section{Introduction}

The Noto Hanto earthquake occurred on 25 March 2007 on the northwestern coast of Noto Peninsula in Ishikawa prefecture, central Japan. This was a shallow, moderatesized earthquake $\left(M_{\mathrm{j}} 6.9\right)$ whose fault plane extended in the NE-SW direction across the coast line and dipped towards the southeast. Seismic intensities of $6+$ on the JMA (Japan Meteorological Agency) scale - the second-largest classwere produced in the alluvium plains within $30 \mathrm{~km}$ from the epicenter, Monzen, Anamizu, and Wajima. Many wooden houses in these areas were damaged, but severe destruction, such as total collapse, was limited to small sub-regions in apparent response to local site effects.

Waveforms of strong ground motion during the mainshock were recorded at seismographs in the intensely shaken areas in the Anamizu and Wajima lowlands. At one of the K-NET (strong-motion seismograph network) stations, ISK005, operated by the National Research Institute for Earth Science and Disaster Prevention in the vicinity of a severely damaged subregion of Amamizu, a peak ground velocity (PGV) of about $100 \mathrm{~cm} / \mathrm{s}$ was observed. At two stations within $1.5 \mathrm{~km}$ of each other in Wajima, ISK003, and JMA Wajima (an alluvium site), a clear contrast was recorded in shaking intensity. PGV at JMA Wajima, in the middle of a severely damaged subregion, was $100 \mathrm{~cm} / \mathrm{s}$, more than twice as large as that at ISK003 $(44 \mathrm{~cm} / \mathrm{s})$ and likely due to a nonlinear soil response.

This paper summarizes some results of our research into ground motions in the damaged areas. We focus mainly on aftershock observations in the Anamizu, Wajima, and

Copyright (c) The Society of Geomagnetism and Earth, Planetary and Space Sciences (SGEPSS); The Seismological Society of Japan; The Volcanological Society of Japan; The Geodetic Society of Japan; The Japanese Society for Planetary Sciences; TERRAPUB
Monzen lowlands in order to evaluate site amplifications and on source modeling in order to estimate ground motions in the lowlands during the 2007 mainshock.

\section{Aftershock Observations}

Aftershock observations were conducted in some of the most intensely shaken lowlands. Eight temporary observation stations had been installed in and around the lowlands by the morning of 27 March 2007, 2 days after the mainshock. Two of these temporary stations were in Anamizu, three were in Wajima, and the remaining three were in Monzen. Each station was equipped with a threecomponent accelerometer, a 24-bit digital recorder with GPS time calibration, and a battery. These instruments recorded ground motions continuously for 3 weeks. The locations of our temporary stations and the permanent KNET stations are shown in Fig. 1 and listed in Table 1. In Anamizu, stations AYK, APO, and ISK005 define a linear array with instrument spacing of approximately $400 \mathrm{~m}$. Station AYK is a rock site on the ridge bounding the eastern Anamizu lowland; APO is an alluvium site between AYK and ISK005; ISK005 is an alluvium site in the vicinity of a severely damaged subregion. In Wajima, stations WFG, WKW, WSB, and ISK003 form a 1.5-km-long linear array with instrument spacings of $200-600 \mathrm{~m}$ spanning the lowland. WFG is a rock site with thin alluvium deposits on the western ridge bounding the lowland; ISK003 is also a rock site on the eastern bounding ridge; WKW and WSB are alluvium sites. In Monzen, all three stations are sited on alluvium sites in severely damaged subregions. MHS and MJD are within $200 \mathrm{~m}$ of the city office where a shaking intensity of 6+ was observed. MTG is in the west of the lowland where the total building collapse rate was the highest of the affected areas. 


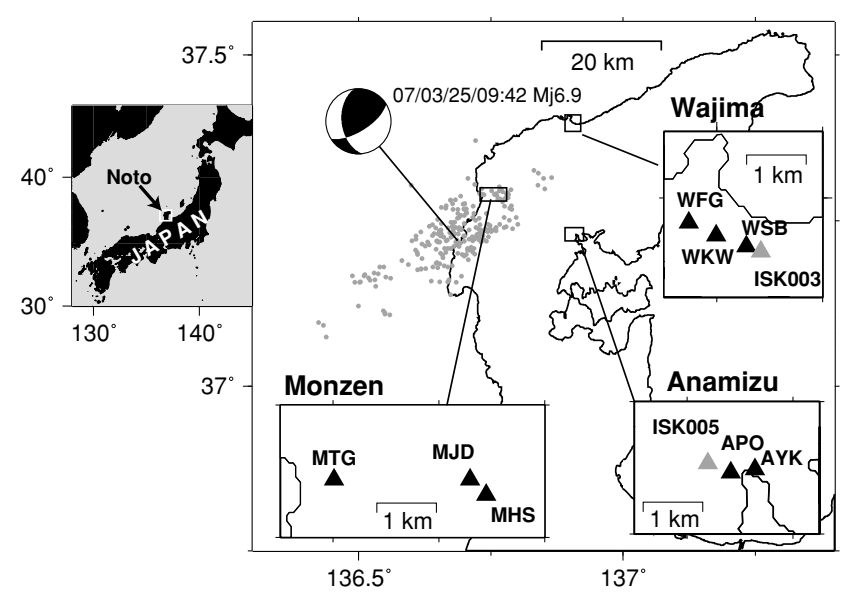

Fig. 1. Locations of temporary seismic observation stations in Monzen, Anamizu, and Wajima. Black triangles are our observation stations. Gray triangles are K-NET stations operated by the National Research Institute for Earth Science and Disaster Prevention (NIED). Gray dots are epicenters of the mainshock and aftershocks $(M \geq 3)$ prior to 6 April 2007, as determined by the Japan Meteorological Agency.

Table 1. List of observation stations in Monzen, Anamizu, and Wajima.

\begin{tabular}{l|cccc}
\hline Station & Latitude & Longitude & Start time & Geology* \\
\hline MHS & 37.28644 & 136.76894 & $03 / 2617: 50$ & alluvium \\
MJD & 37.28875 & 136.76589 & $03 / 2710: 25$ & alluvium \\
MTG & 37.28872 & 136.74017 & $03 / 2709: 10$ & alluvium \\
AYK & 37.22975 & 136.91278 & $03 / 2612: 00$ & rock \\
APO & 37.22930 & 136.90822 & $03 / 2612: 30$ & alluvium \\
WSB & 37.39267 & 136.90556 & $03 / 2615: 25$ & alluvium \\
WKW & 37.39436 & 136.89986 & $03 / 2616: 00$ & alluvium \\
WFG & 37.39628 & 136.89467 & $03 / 2616: 30$ & rock \\
\hline
\end{tabular}

*Ishikawa Pref. (1991, 1993).

\section{Analysis of Aftershock Records}

A large number of aftershocks were successfully recorded. In Fig. 2, we show examples of observed ground accelerations at our temporary stations and the nearby K-NET stations, ISK003 and ISK005, during the events at 10:51 (JST) on 28 March 2007 and 15:18 (JST) on 6 April 2007. The waveforms have been bandpass-filtered to between 0.05 and $24 \mathrm{~Hz}$. The horizontal peak values of ground acceleration at the alluvium sites span similar ranges to those at the rock sites. However, the waveforms at the alluvium sites are distinguishable by their pronounced lowfrequency components, which indicate site amplification.

The spectral amplitude ratios of the alluvium sites APO, ISK005, WSB, and WKW with respect to the rock sites in the frequency range $0.2-10 \mathrm{~Hz}$ are illustrated in Fig. 3. Stations AYK and ISK003 have been selected as the reference sites in Anamizu and Wajima, respectively. The horizontal components of 15 aftershocks in Anamizu and 12 aftershocks in Wajima, with JMA magnitudes of 3.5-4.9, are shown. Smoothing with a $0.2-\mathrm{Hz}$ bandwidth Parzen Window has been applied in calculating the spectral ratios. The time window is $10.25 \mathrm{~s}$ long and starts at the $S$-wave onset. Predominant frequencies are approximately $1 \mathrm{~Hz}$ for all the station pairs. Large amplitude ratios of 5-20 are obtained at the spectral peaks.
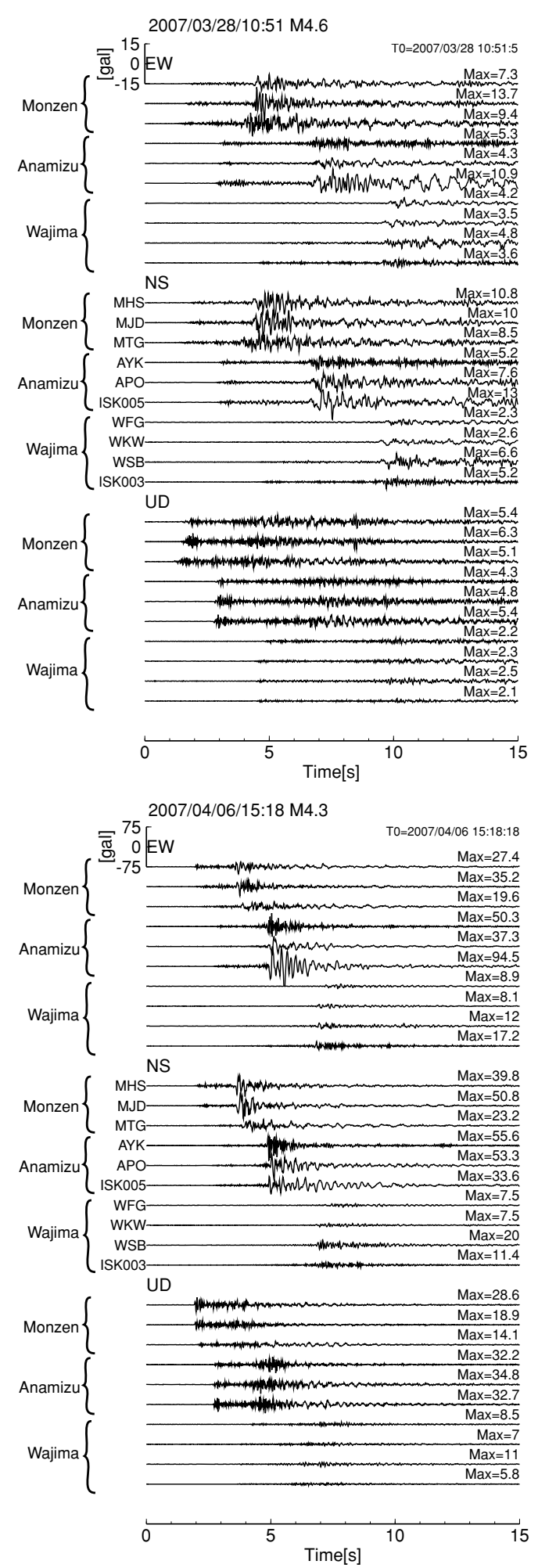

Fig. 2. Acceleration waveforms observed at our temporary arrays and K-NET stations. Upper: the event at 10:51 (JST) on 28 March 2007. Lower: the event at 15:18 (JST) on 6 April 2007. From top to bottom: the NS, EW, and UD components of each station. AYK, WFG, and ISK003 are rock sites.

Theoretical spectral ratios calculated from 1-D velocity structures (Fig. 4) are illustrated as solid curves in Fig. 3. The 1-D structure for ISK005 is inferred from $P-S$ logging data at the site. Structures for the other stations are modeled manually based on logging parameters from nearby bore- 

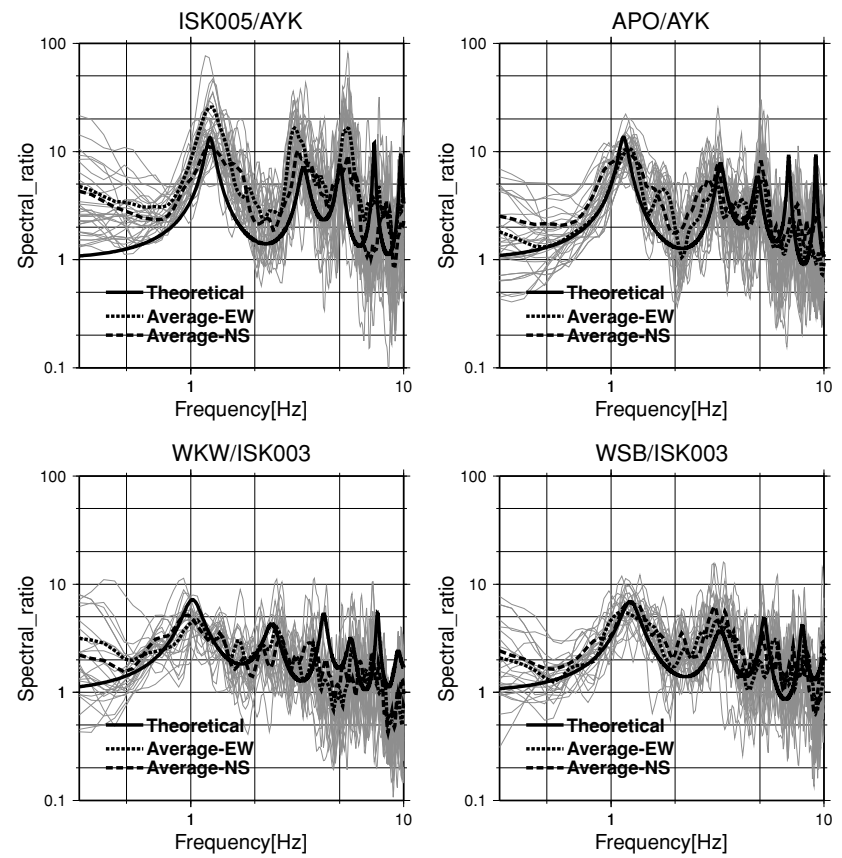

Fig. 3. Amplitude spectral ratios of the horizontal components of alluvium sites with respect to the reference sites (AYK for stations in Anamizu and ISK003 for stations in Wajima) in Anamizu (upper) and Wajima (lower). Broken lines show the averages of the ratios. Solid lines are theoretical spectral ratios from 1-D velocity structures (Fig. 4) with a $1-\mathrm{D}$ theoretical response analysis.

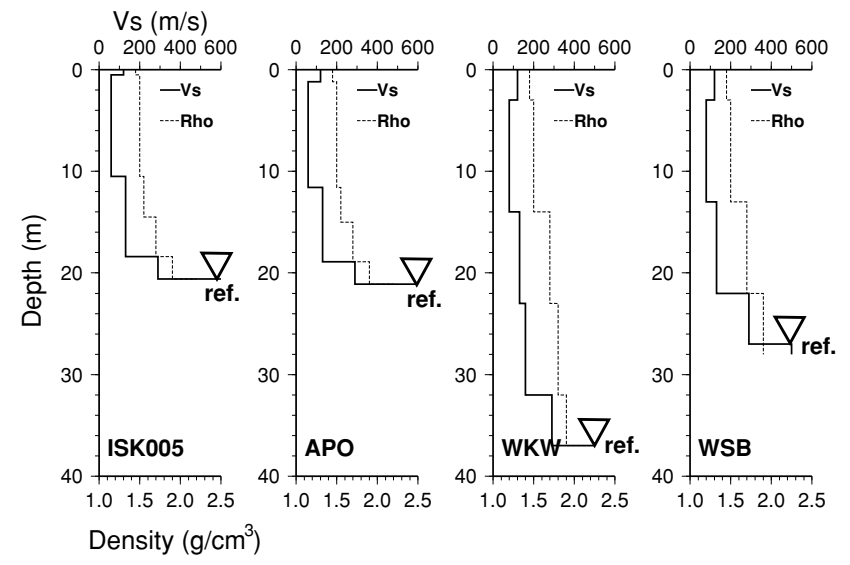

Fig. 4. 1-D subsurface velocity structure models, $S$-wave velocity and density, for alluvium sites in Anamizu and Wajima. Inverted triangles denote the depths of the reference layers assumed in the 1-D response analysis.

holes, such as $N$-values of the SPT (standard penetration test) and lithology (Sato, 1994), in order to fit the frequencies of peaks and troughs in the theoretical spectral ratios to the observations. The $S$-wave velocities of the reference layers are assumed to be $600 \mathrm{~m} / \mathrm{s}$ and $500 \mathrm{~m} / \mathrm{s}$ at AYK and ISK003, respectively. The attenuation factor for each layer is given as a function of $S$-wave velocity depending on the type of soil after Kobayashi et al. (1999) and Kyuke et al. (1999). The depths to the basement of the 1-D structures in Wajima are consistent with those estimated by Sato (1994).

The frequencies and amplitudes of the theoretical spectral peaks agree well with the observed ones at frequencies

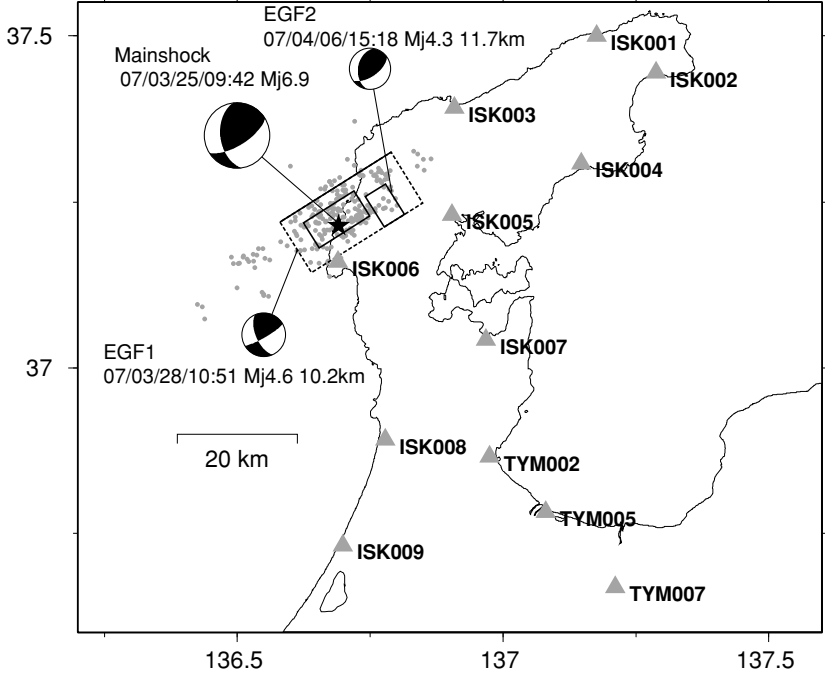

Fig. 5. Location map of the K-NET observation stations and epicenters of the aftershocks used as empirical Green's functions. The largest rectangle on the focal area indicates the fault plane assumed in the forward modeling of the mainshock, and the other rectangles are estimated asperities. The fault plane is $22 \mathrm{~km}$ (along-strike) by $20 \mathrm{~km}$ (down-dip), the strike is $58^{\circ}$, and the dip is $60^{\circ}$. The star shows the location of the rupture nucleation point.

of up to approximately $5 \mathrm{~Hz}$. We have confirmed that with these 1-D structures the ground motions during aftershocks at the alluvium sites, except at ISK005, are well reproduced from the ground motions at the reference sites using a 1-D response analysis. The amplitude ratios at ISK005 are several times greater than those at APO, though the frequencies of the spectral peaks are similar, indicating similar velocity structures in the linear 1-D regime. The observed waveforms at ISK005 are characterized by a large $S$-wave component and later phases several times larger than those seen at APO (see Fig. 2). Large amplification of the $S$-wavetrain can be accounted for if the acoustic impedance at the rocksediments boundary is made larger. However, the later phases cannot be reproduced by a 1-D analysis. Moreover, the amplification of the EW component of ISK005 is about twice that of the NS component (see Fig. 3). We conclude, therefore, that ISK005 is one location where 2-D or higherdimensional amplification effects predominate.

\section{Source Modeling of the Mainshock Using the Empirical Green's Function Method \\ 4.1 Data and method}

We have determined a mainshock source model that yields broadband ground motions consistent with observations using a forward modeling approach incorporating the empirical Green's function method (Irikura, 1986; Kamae and Irikura, 1998). We seek a source model composed of two asperities, as two distinct pulses can be recognized in some of the observed waveforms. Two aftershocks, referred to hereafter as aftershock-1 and aftershock-2, are selected as sources for the empirical Green's functions (EGFs). Both have focal mechanisms similar to that of the mainshock, and their waveforms are recorded at our temporary stations as well as at K-NET stations within $100 \mathrm{~km}$ of the epicenter. The locations of the K-NET stations that recorded both 
Table 2. Source parameters of the mainshock.

\begin{tabular}{lc}
\hline & Mainshock \\
\hline Origin time* $(\mathrm{JST})$ & $2007 / 03 / 2509: 41: 57.9$ \\
Hypocenter* $^{*}$ & $(136.686 \mathrm{E}, 37.221 \mathrm{~N}, 10.7 \mathrm{~km})$ \\
$M_{\text {JMA }}{ }^{*}$ & 6.9 \\
Seismic moment $(\mathrm{N} \mathrm{m}) * *$ & $1.36 \times 10^{19}$ \\
Focal mechanism** & $(58,66,132)$ \\
(Strike, dip, rake) & $(173,48,34)$ \\
\hline
\end{tabular}

Table 3. Source parameters of the aftershocks used as empirical Green's functions.

\begin{tabular}{lc}
\hline & Aftershock-1 \\
\hline Origin time* $(\mathrm{JST})$ & $2007 / 03 / 2810: 51$ \\
Hypocenter* & $(136.612 \mathrm{E}, 37.176 \mathrm{~N}, 10.2 \mathrm{~km})$ \\
$M_{\mathrm{JMA}}$ & 4.6 \\
$M_{\mathrm{o}}(\mathrm{N} \mathrm{m}) * *$ & $1.29 \times 10^{15}$ \\
Area $\left(\mathrm{km}^{2}\right)$ & 1.21 \\
$\Delta \sigma(\mathrm{MPa})^{* * *}$ & 2.36 \\
\hline \hline & Aftershock-2 \\
\hline Origin time* $(\mathrm{JST})$ & $2007 / 04 / 0615: 18$ \\
Hypocenter* & 4.3 \\
$M_{\mathrm{JMA}}$ & $8.18 \times 10^{14}$ \\
$M_{\mathrm{o}}(\mathrm{N} \mathrm{m}) * *$ & 0.64 \\
Area $\left(\mathrm{km}^{2}\right)$ & 3.89 \\
$\Delta \sigma(\mathrm{MPa}) * * *$ & $\mathrm{E}, 37.267 \mathrm{~N}, 11.7 \mathrm{~km})$ \\
\hline$* \mathrm{JMA}, * * \mathrm{~F}-$ net, $* * *$ Brune & $(1970,1971)$.
\end{tabular}

aftershocks are shown in Fig. 5 together with the epicenters and the focal mechanisms of the mainshock and the EGF aftershocks. The locations of the assumed fault plane and the computed asperities are also shown. The fault plane's location is based on fault models proposed from coastal deformation (Awata et al., 2008), GPS and InSAR (Geographical Survey Institute, 2007), and strong motion inversion (Horikawa, 2008). Tables 2 and 3 list the source parameters of the mainshock and aftershocks, respectively. The source parameters of the aftershocks, rupture area, and stress drop are estimated from displacement source spectra computed from acceleration data recorded at KiK-net borehole stations ISKH02, ISKH03, ISKH04, and GIFH10 (Brune, 1970, 1971; Madariaga, 1976).

\subsection{Source model and synthetics}

The source model obtained from the forward modeling is shown in Fig. 6 and annotated with the source parameters of each asperity. Rupture starts at the nucleation point and propagates radially at a velocity of $2.8 \mathrm{~km} / \mathrm{s}$. An $S$-wave velocity of $3.5 \mathrm{~km} / \mathrm{s}$ is assumed along the wave propagation path. Aftershock records bandpass-filtered to between 0.2 and $10 \mathrm{~Hz}$ are used as EGFs. The waveforms from aftershock-1 and aftershock-2 are used for synthesizing waveforms from the eastern asperity (Asp1) and the western asperity (Asp2), respectively. Asp1 accounts for the overall features of waveforms recorded in the north and the southwest of the Noto Peninsula, but Asp2 is required to reproduce the sharp velocity pulses seen in the waveforms from ISK005 and ISK007. The seismic moments released from the asperities are estimated to be $3.76 \times 10^{18} \mathrm{~N} \mathrm{~m}$

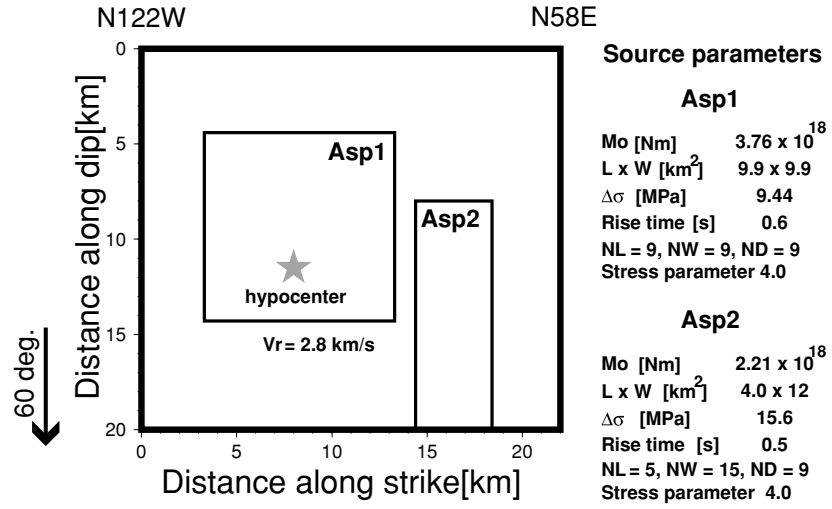

Fig. 6. Source model composed of two asperities, Asp1 and Asp2, obtained from forward modeling. Rupture propagates at the velocity $2.8 \mathrm{~km} / \mathrm{s}$ from the rupture nucleation point shown as a gray star. Source parameters for the asperities, seismic moment: $M_{\mathrm{O}}(\mathrm{N} \mathrm{m})$, asperity size: $L \times W\left(\mathrm{~km}^{2}\right)$, stress drop: $\Delta \sigma(\mathrm{MPa})($ Brune, 1970, 1971), rise time, scaling parameters (NL, NW, ND), and stress parameter are listed.

for Asp1 and $2.21 \times 10^{18} \mathrm{~N} \mathrm{~m}$ for Asp2, the sum of which amounts to about $44 \%$ of the whole event.

Comparisons of the synthetic and observed waveforms at six stations are presented in Fig. 8 and pseudo-velocity response spectra (PVRS) for the waveforms at all the stations in Fig. 5 are shown in Fig. 7. The velocity and displacement synthetic waveforms and their peak values show good agreement with the observed ones for all the stations and components-with the exception of the NS component at ISK006. The PGVs of the synthetic waveforms are 70$150 \%$ of those observed. The envelopes of the synthetic acceleration waveforms are also consistent with the observations for all stations-except for ISK006 and ISK005. The poor fit of the displacement waveforms at ISK006, especially for the NS component, is attributable to a difference in the radiation coefficient between aftershock- 1 and the mainshock produced by the large azimuth discrepancy. The PVRS values of the synthetics agree well with those of the observations over a broad period range. However, at the shorter-period end of the PVRS spectrum (0.1-0.2 s), the horizontal components at stations ISK005 and ISK007, both of which are alluvium sites, are overestimated by several fold, whereas the vertical components are reasonably well matched. This indicates some degree of nonlinear soil behavior at those stations.

We have also estimated strong ground motions during the mainshock at our temporary stations. Synthetic ground velocities from the source model are shown in Fig. 9. The waveforms at every alluvium site show significant pulselike waves followed by monotonic later phases, and the PGVs are two- or three-fold larger than those at nearby rock sites. The calculated PGVs for the alluvium sites are 70 $110 \mathrm{~cm} / \mathrm{s}$ in Monzen, 60-110 cm/s in Anamizu, and 40$50 \mathrm{~cm} / \mathrm{s}$ in Wajima. Since the synthetic PGV at ISK003 in Wajima is $70 \%$ of the observed PGV, we simply correct PGVs at the alluvium sites in Wajima to $60-70 \mathrm{~cm} / \mathrm{s}$.

\section{Conclusion}

Linear array observations of aftershocks following the Noto Hanto earthquake in three of the most affected low- 
ISK001

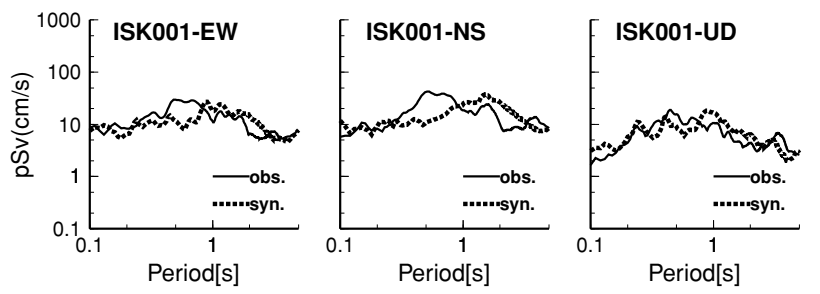

ISK003

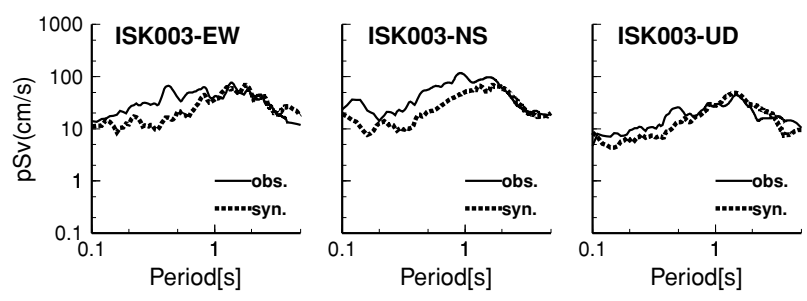

ISK005

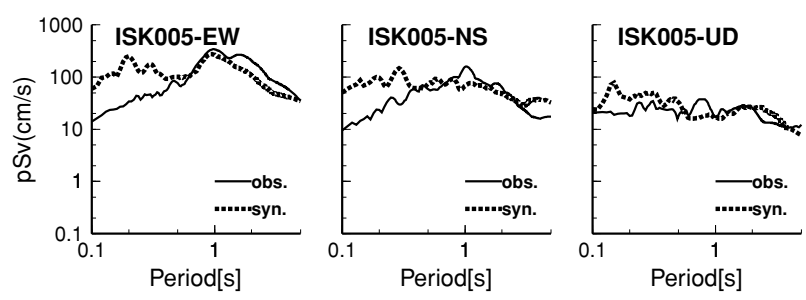

ISK007

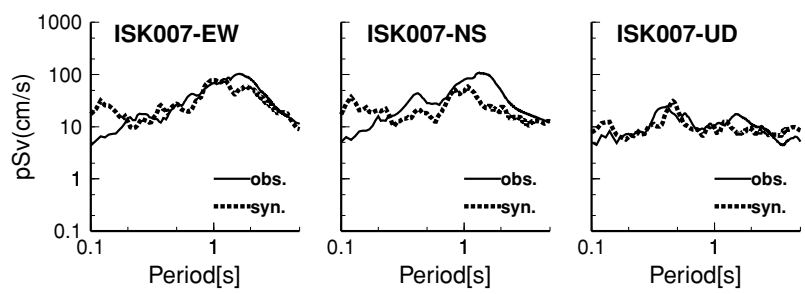

ISK009

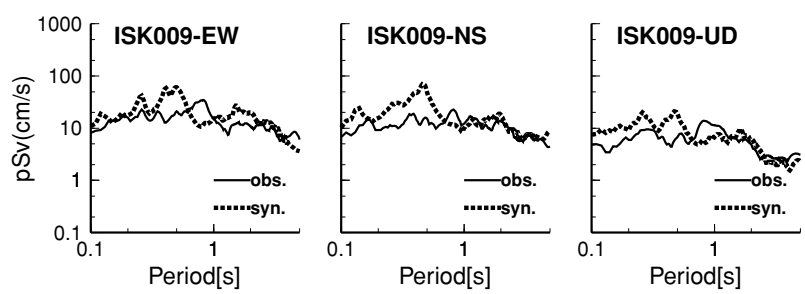

TYM005

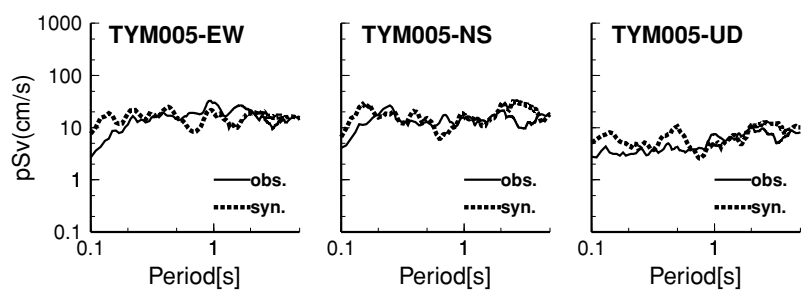

ISK002

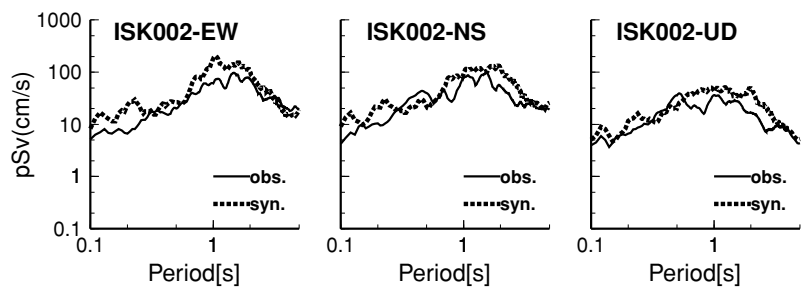

ISK004

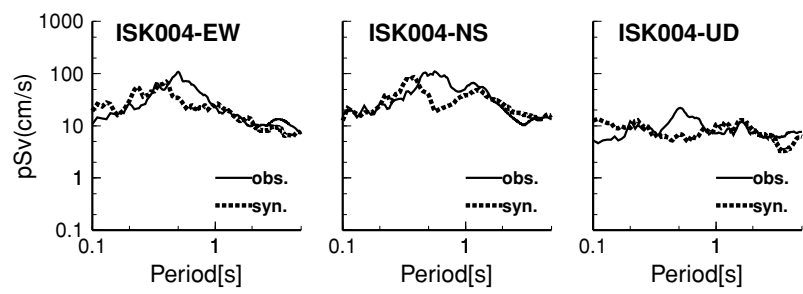

ISK006

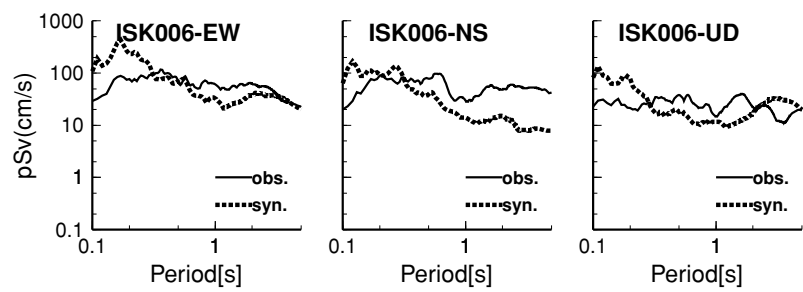

ISK008

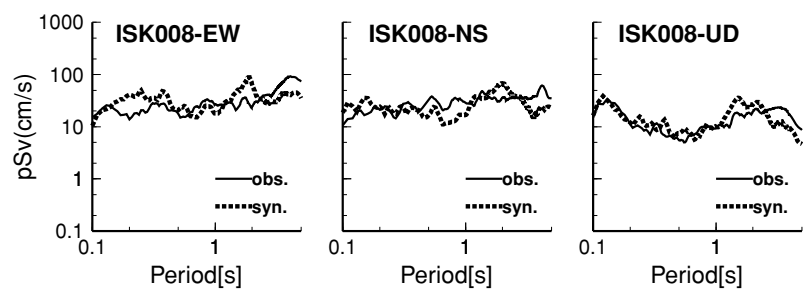

TYM002

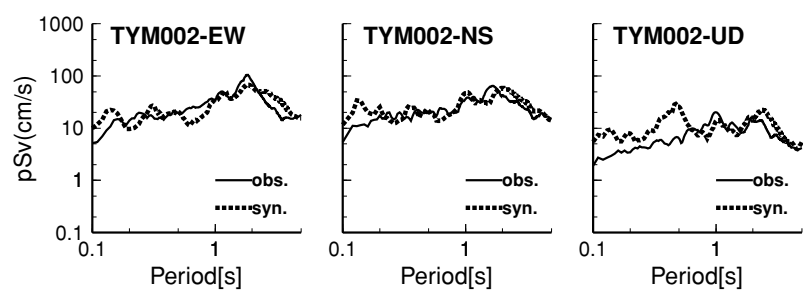

TYM007

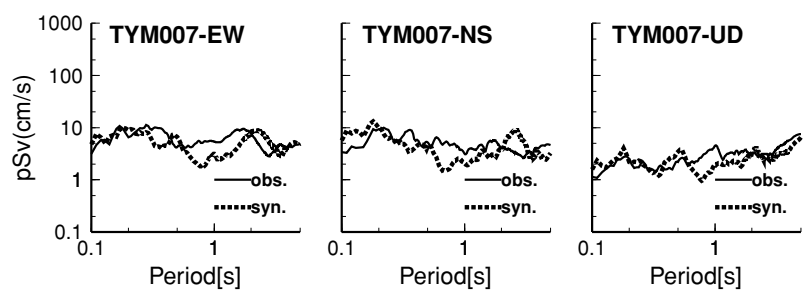

Fig. 7. Comparison of the pseudo-velocity response spectra with a damping factor 0.05 of the synthetic (bold broken) and the observed (thin solid) ground motions at the K-NET stations shown in Fig. 5.

lands have revealed site amplification at the alluvium sites which resulted in severe damage. Site amplifications at alluvium sites in Anamizu and Wajima have predominant frequencies of approximately $1 \mathrm{~Hz}$ and spectral ratios with respect to rock sites that are five- to twenty-fold larger. These amplifications are reproduced well with a linear 1-D model-except at ISK005 in Anamizu.

A proposed source model comprising two asperities successfully reproduces ground motions during the mainshock using the empirical Green's function method. The seismic moment released at the asperities-3.76 $\times 10^{18} \mathrm{~N} \mathrm{~m}$ at Asp1 and $2.21 \times 10^{18} \mathrm{~N} \mathrm{~m}$ at Asp2-is about $44 \%$ that 

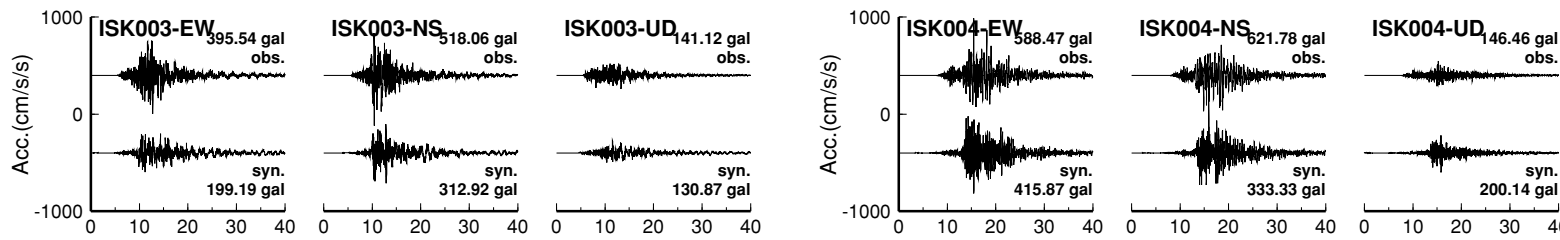

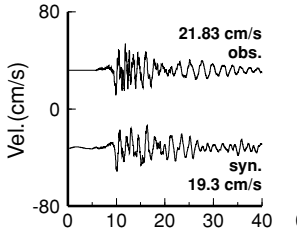
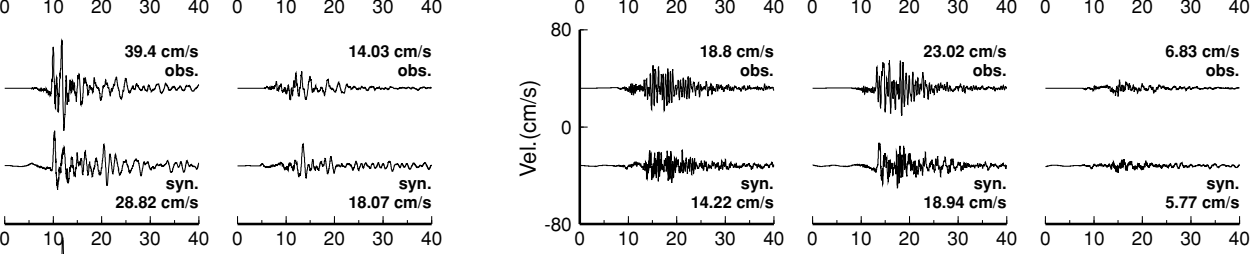

Time(s)

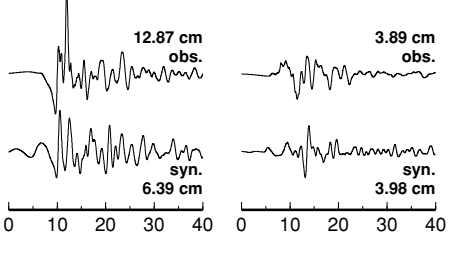


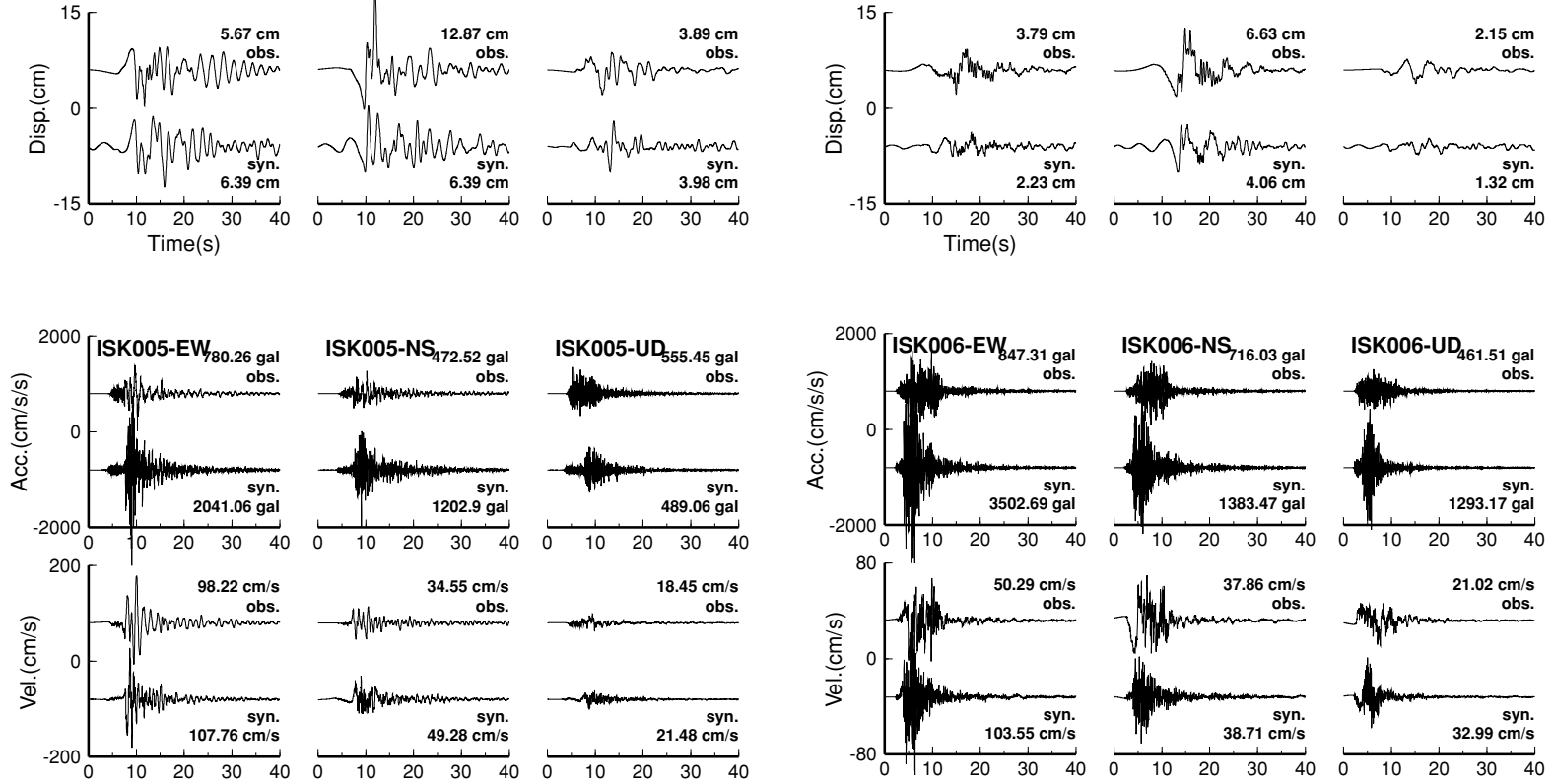

它
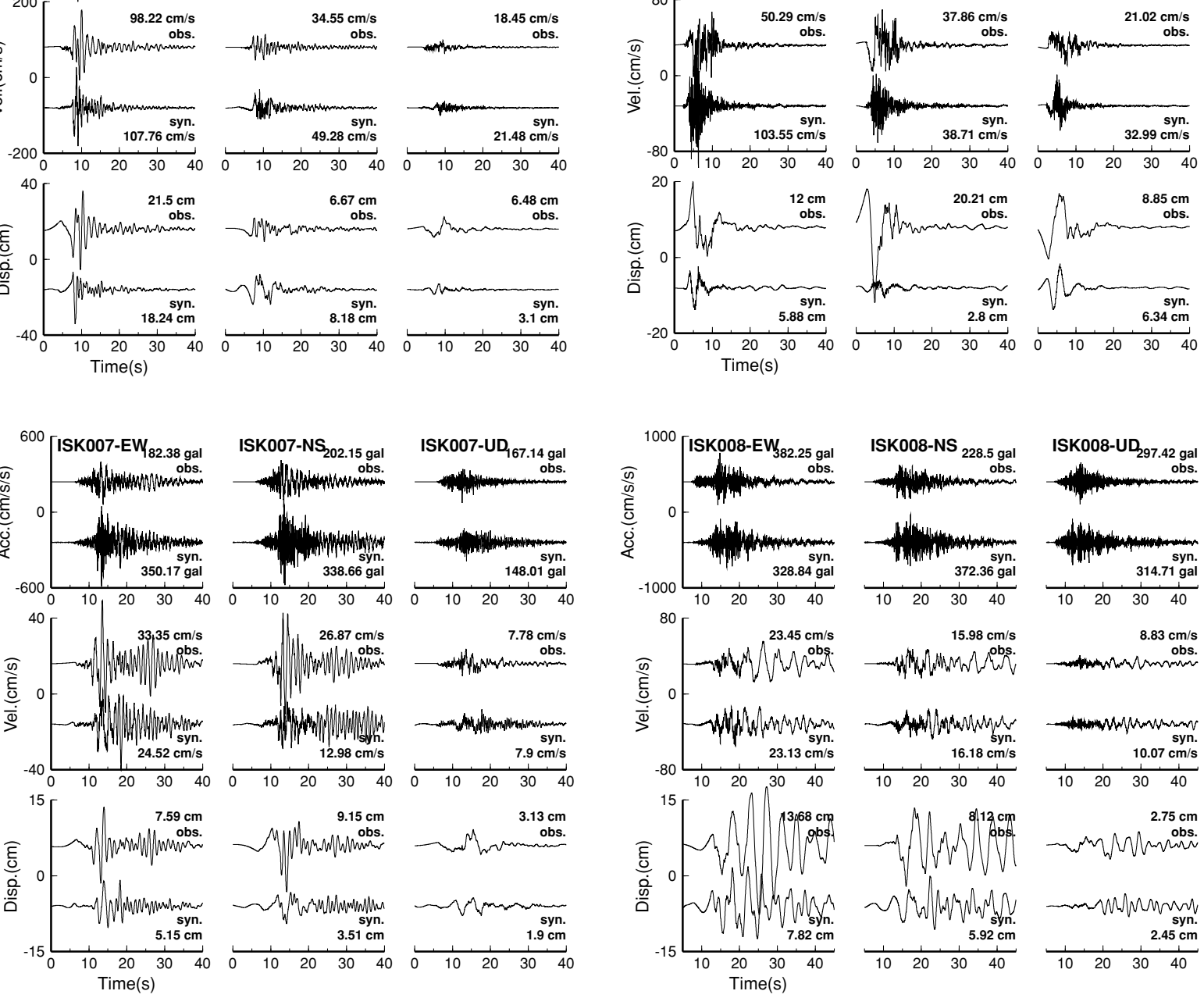

why Whins

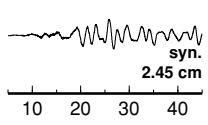

Fig. 8. Comparison of the waveforms of the observed (top) and the synthetic (bottom) ground motions at ISK003, ISK004, ISK005, ISK006, ISK007, and ISK008. Numerics are maximum amplitudes. Time is from the origin time. Top: accelerations, Middle: velocities, Bottom: displacements for each station. 


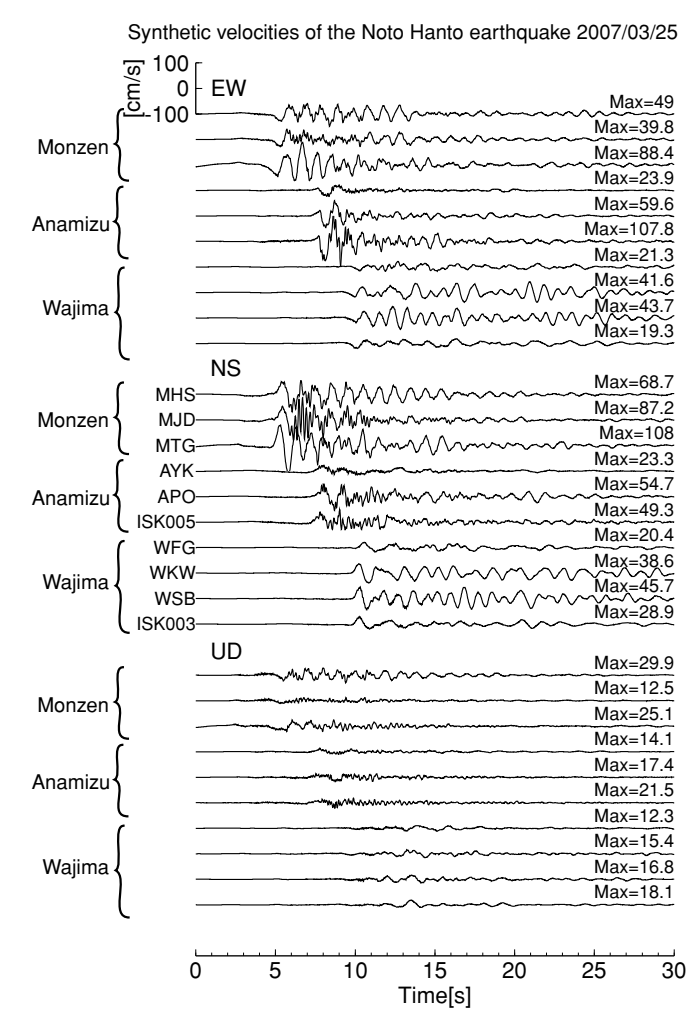

Fig. 9. Synthetic ground velocities at all the temporary array stations computed from our source model using the empirical Green's function method.

of the whole event. Peak ground velocities (PGV) at the alluvium sites of our array stations during the mainshock are estimated to have been approximately $70-110 \mathrm{~cm} / \mathrm{s}$ for Monzen, $50-110 \mathrm{~cm} / \mathrm{s}$ for Anamizu, and $60-70 \mathrm{~cm} / \mathrm{s}$ for Wajima.

Acknowledgments. We thank Dr. Hidetaka Saomoto and Dr. Ikuo Cho for assisting our aftershock observation. Fruitful discussions with Dr. Haruko Sekiguchi at GSJ, AIST, are greatly appreciated. The manuscript was improved by reviews from two anonymous reviewers. This study has been partially supported by a Grant-in-Aid for Special Purposes, "Urgent research on the aftershocks of the 2007 Noto Hanto earthquake" Special Coordination Funds, from the Ministry of Education, Culture, Sports, Science and Technology (MEXT). A portion of the ground motion data set used in this study was recorded by K-NET and KiK-net operated by the National Research Institute for Earth Science and Disaster Prevention. Some of the figures were drawn using Generic Mapping Tool (Wessel and Smith, 1998).

\section{References}

Awata, Y., S. Toda, T. Azuma, H. Kaneda, and H. Horikawa, Coastal deformation associated with the 2007 Noto Hanto earthquake, central Japan, determined by uplifted and subsided intertidal organisms, Earth Planets Space, 2008 (in press).

Brune, J. N., Tectonic stress and the spectra of seismic shear waves from earthquake, J. Geophys. Res., 75, 4997-5009, 1970.

Brune, J. N., Correction, J. Geophys. Res., 76, 5002, 1971.

Geographical Survey Institute, Leveling survey in the focal area of the Noto Hanto earthquake, 2007, http://www.gsi.go.jp/WNEW/PRESSRELEASE/2007/0711.htm, 2007 (in Japanese).

Horikawa, H., Characterization of the 2007 Noto Hanto, Japan, earthquake, Earth Planets Space, 2008 (in press).

Irikura, K., Prediction of strong acceleration motion using empirical Green's function, Proc. 7th Japan Earthquake Symp., 151-156, 1986.

Ishikawa Prefecture, Subsurface geological map Anamizu, Togi, Tsurugiji, 1991.

Ishikawa Prefecture, Subsurface geological map Wajima, 1993.

Kamae, K. and K. Irikura, Source model of the 1995 Hyogo-ken Nanbu earthquake and simulation of near-source ground motion, Bull. Seis. Soc. Am., 88, 400-412, 1998.

Kobayashi, K., H. Kyuke, T. Uetake, M. Mashimo, and H. Kobayashi, Estimation of Q value for soil layers by simultaneous inversion of transfer functions at many sites: Part 3, Annual Meeting, Arch. Inst. Jpn., B-2, 253-254, 1999 (in Japanese).

Kyuke, H., K. Kobayashi, T. Uetake, M. Mashimo, and H. Kobayashi, Estimation of Q value for soil layers by simultaneous inversion of transfer functions at many sites: Part 4, Annual Meeting, Arch. Inst. Jpn., B-2, 255-256, 1999 (in Japanese).

Madariaga, R., Dynamics of an expanding circular fault, Bull. Seis. Soc. Am., 66, 639-666, 1976.

Sato, Y., Subsurface structure of Wajima urban area, Hokuriku Jiban Joho (Report of Hokuriku Geothech. Association), 4, 1994 (in Japanese).

Wessel, P. and W. H. F. Smith, New, improved version of Generic Mapping Tools released, EOS, 79, 579, 1998.

M. Yoshimi (e-mail: yoshimi.m@aist.go.jp) and K. Yoshida 